B. APL, $42.2006(33-68)$

\title{
CATEGORÍAS MORFOSINTÁCTICAS COMUNES AL CASTELLANO, LATÍN Y GRIEGO PARA UN ESTUDIO FUNCIONAL DE LAS LENGUAS CLÁSICAS
}

\section{CATEGORIES MORPHOSYNTAXIQUES COMMUNES À L'ESPAGNOL, LE LATIN ET LE GREC POUR UNE ÉTUDE FONCTIONNEL DES LANGUES CLASSIQUES}

\author{
Ana María Gispert-Sauch Colls \\ Universidad Nacional Mayor de San Marcos
}

Resumen:

El presente estudio trata de sistematizar las nociones básicas gramaticales que son comunes a las lenguas castellana, latina y griega, y las que son peculiares y propias del latín o del griego.

La autora elige como hilo conductor el criterio de funcionalidad, bajo el cual analiza las cuatro categorías morfológicas básicas: nombre, adjetivo, verbo y adverbio, presentando la función que es propia de cada una de ellas pero señalando, a la vez, cómo estas funciones sintácticas pueden estar expresadas por otras realizaciones morfológicas.

\section{Résumé:}

Le présent étude essaie de systématiser les notions de base grammaticales qui sont communes á la langue castillanne, latine et grecque et celles qui sont particulières et propres de le latin et le grec. On choisit comme fil conducteur 
le critère de fonctionalité, sous lequel on analyse les quatre catégories morphologiques de base: nom, adjective, verbe et adverbe, en présentant la fonction qui est propre de chacune de d'elles mais en indiquant, à la fois, comme ces fonctions syntaxiques peuvent éter exprimes par d'autres réalisations morphologiques.

Palabras clave:

Categorías morfosintácticas, castellano, latín, griego

Mots clef:

Catégories morpho-syntaxiques, castillan, latin, grec

\section{Introducción}

En los estudios filológicos y gramaticales se observa una pluralidad de enfoques o perspectivas que, asumiendo una terminología variopinta, conlleva a menudo dificultades en la comprensión y en la metodología de la investigación. Hay un metalenguaje lingüístico y gramatical que induce a la confusión. Ya Ferdinand Saussure, atento a esta ambigüedad, expresaba: "Desde un punto de vista práctico, sería interesante comenzar por las unidades, para determinarlas y hacerse idea de su diversidad clasificándolas (...) No se puede decir que alguna vez se hayan colocado los lingüistas ante este problema, ni que se haya comprendido su importancia y su dificultad; en materia de lengua siempre se han contentado los investigadores con operar sobre unidades mal definidas...".

La primera dificultad está, a mi parecer, en la "proliferación" terminológica y en la diversidad de modelos teóricos lingüísticos a lo largo de la historia. Así tenemos que en la Roma antigua predominaba el criterio morfológico. Ejemplo de ello fue Varrón, quien distinguió para la lengua latina cuatro clases de palabras según las categorías gramaticales de cada una: nombre (poseedor de caso pero carente de tiempo), verbo (con tiempo

Curso de lingüística general. Ed. Alianza, Madrid. Pág. 184 (El subrayado es nuestro) 
pero sin caso), participio (con las categorías de caso y tiempo) y partículas (carentes de caso y de tiempo).

Otro criterio, el lógico-objetivo, relaciona las partes de la oración con sus respectivas categorías lógicas: el nombre correspondería al concepto de sustancia, el adjetivo al de cualidad, el verbo correspondería a la acción y el adverbio a la modalidad. La crítica a esta clasificación es obvia, pues el sustantivo puede indicar tanto acción (ej. la corrida) como cualidad (ej. la pequeñez) etc. Y el adjetivo puede indicar acción (ej. el pueblo defensor) o modalidad (ej. ciudades semejantes), o el verbo puede no significar acción (ej. él es cantor)... Es decir: una misma realidad puede ser denotada por distintas clases de palabras.

El criterio funcional se basa en la función sintáctica que desempeñan las palabras en la oración. Es el criterio que asumió en lo fundamental Andrés Bello, y así las palabras quedaban clasificadas de la siguiente forma: sustantivo (sujeto de la proposición), adjetivo (modificador del sujeto), verbo (predicado de la proposición), adverbio (modificador del predicado), preposición (iniciador de un complemento), conjunción (nexo entre palabras y frases).

Consecuencia de esta primera dificultad es la mezcla indiscriminada de criterios (una especie de eclecticismo), que abunda en los estudios, artículos o manuales de escolares. Muchos de estos estudios se inscribieron dentro del modelo que llamamos gramática tradicional, cuya finalidad era la descripción de la lengua, que en realidad era muy intuitiva y repleta de "excepciones" que escapaban a la supuesta norma general.

Una segunda dificultad, relacionada con la anterior, es la cantidad de definiciones existentes para una misma unidad o categoría gramatical. El caso más evidente es el de la "oración", la cual puede ser considerada desde el punto de vista psicológico, lógico y gramatical ${ }^{2}$, según se considere la

S. Gili Gaya considera que hay oración cuando se dan los tres criterios complementarios: el psicológico, de atención por parte del hablante, que se manifiesta en la curva melódica y se caracteriza por la intención expresiva con 
orientación comunicativa, la intencional o la orientación morfo-funcional. Y dentro del punto de vista gramatical, la oración puede ser analizada semánticamente (la oración es la menor unidad del habla que comunica un sentido completo), o fónicamente (la oración es una unidad entre pausas), o bien sintácticamente (la oración es toda forma lingüística que no está incluida en otra más amplia; es, pues, independiente) $)^{3}$.

Por otra parte, en algunos casos faltan categorías necesarias para la teoría y el análisis sintáctico. Es el caso de los "sintagmas" (conglomerados de palabras que se funden en un bloque significante y se influyen mutuamente), imprescindibles para las lenguas románicas pero no tanto para las gramática griega y latina.

Las unidades lingüísticas en su conjunto siguen siendo una cuestión abierta en el siglo XXI. La existencia de una unidad intermedia entre palabra y oración no está definida consensualmente: Saussure, D. Alonso, G. Rojo, entre otros, definen esta unidad como "sintagma", combinación de elementos gramaticales con un significado resultante de dicha fusión. Para otros, es una frase, un sintaxema, un grupo de palabras, una microestructura, etc. ${ }^{4}$ Juan Alcina Franch define la frase por el aspecto negativo de ausencia de verbo en forma personal, pero sí pueden aparecer en ella infinitivos o gerundios (ej. prohibidofumar). ${ }^{5}$

Si nos referimos a las nociones oración y proposición, ocurre algo parecido. La sintaxis tradicional combinaba sin criterio fijo ambas nociones.

que ha sido proferida; el criterio lógico, oración es la expresión verbal de un juicio que comprende sujeto y predicado; y el gramatical, por el cual la oración es el conjunto de palabras/frases que se relacionan de forma inmediata con un verbo en forma personal. Para A. Alonso y H. Ureña, las palabras conforman una oración sólo por el contenido o por la forma (sujeto y predicado).

Alonso Marcos, A. Glosario de la terminología gramatical. Ministerio de Educación y Ciencia. Madrid, España. 1985.

4 Jiménez Cano, José María: "Las unidades lingüísticas: ¿una cuestión cerrada? en Revista electrónica de Estudios Filológicos, № 2, noviembre 2001.

5 Alcina Franch, Juan, "Spanisch Syntax" en Lexikon der Romanistischen Linguistik. Tubingen, Alemania. 1992. 
I a gramática estructuralista propone indistintamente dos unidades: nexus/ crcción; cláusula/oración. Al respecto, M. Lope Blanch toma el uso de cláusula como "expresión autónoma desde el punto de vista de la elocución", sin f r rma gramatical determinada y entre dos pausas. Y reserva el término oración para el segmento entre cuyos elementos existe una función predicativa.

En este aspecto, M. Lope Blanch coincide con Fuentes Rodríguez para quien oración "es el constructo abstracto (estructura de predicación: sintagma nominal + sintagma verbal, la más frecuente), objeto de estudio de la gramática", y emplea el término enunciado para la mínima manifestación con sentido de un hablante a un oyente en una situación concreta de comunicación. Es, por tanto, una unidad del habla que no puede analizarse fuera de su contexto comunicativo". Distingue, pues, como Saussure, el aspecto de lengua del de habla ${ }^{6}$. El hablante elige conscientemente la estructura gramatical de su enunciado de acuerdo con su intención comunicativa. Ésta podrá ser una enunciación (afirmativa o negativa), una pregunta, un deseo o un mandato. Para la gramática generativa, por su parte, la oración es cualquier estructura superficial que no sea agramatical. La oración pertenece a la competencia lingüística del hablante, y no a la actuación.

Si hemos esbozado aquí algunas de las definiciones de oración es sólo para dar cuenta de la complejidad del tema. J. Ries citaba 139 definiciones de oración. No es nuestro objetivo juzgar cuál de ellas es una definición completa, verdadera y total, sino dar cuenta de que las definiciones varían según atiendan a la forma de expresión, al contenido o a las funciones.

Será necesario, para nuestro estudio, partir de algún criterio que atraviese, cual hilo conductor, nuestra reflexión.

Fuentes Rodríguez C. La sintaxis de los relacionantes supraoracionales. Ed. Arco Libros. Madrid. 1996. 


\section{PRIMERA PARTE}

\section{La Cuestión de Criterios y Nomenclatura}

Trataremos én este estudio de buscar un criterio que ayude a entender mejor la sintaxis, y éste será el criterio de la funcionalidad. Sin embargo, para llevar a término dicho criterio, deberemos montarlo sobre el sistema morfológico. Nuestras lenguas de análisis (castellano, griego y latín) tienen características diversas, pero consideramos que tienen puntos comunes que servirán de apoyatura para nuestra profundización. Para ello, mostraremos cuál es el punto de partida de nuestra concepción de lengua y de clases de palabra.

Partimos de que la lengua es un código de signos lingüísticos. Éstos son o bien signos léxicos (constituyen el vocabulario de cada lengua) o bien signos gramaticales (relacionan los distintos términos del vocabulario en la lengua escrita o hablada). El estudio y la enseñanza común tradicional, en lo que respecta a la gramática, separan lo que corresponde al léxico de lo que corresponde a la sintaxis. Separan la "morfología" de la "sintaxis", resultando, de este modo, grandes vacíos en el análisis de frases que, en el habla, quedan sin poder ser encasilladas por falta de categorías adecuadas y de una metodología que supere la dicotomía morfología/sintaxis e integre de alguna manera el aspecto semántico.

Al estudiar sistemáticamente la morfología del castellano, una de las primeras clasificaciones que encontramos es la referente a las categorías de palabras (artículo, nombre, adjetivo, pronombre, verbo, adverbio, preposición, conjunción e interjección), y en un segundo momento se estudian las funciones. En el caso del latín y griego, al ser lenguas de flexión con sus determinados casos, cada uno de ellos representa una función dentro de la oración, y no es posible analizar la palabra en sí, si no es ya en un caso determinado. Eso obliga a que, desde un comienzo, se estudie en las lenguas clásicas —objeto de nuestro estudio- la morfología de los casos ligada a su aspecto sintáctico. El "caso", pues, es la categoría primordial gramatical en las lenguas latina y griega que indica la relación de un nombre o adjetivo con los elementos de su oración. 
El criterio que trataremos de aplicar a las tres lenguas propuestas castellano, griego y latín- (que están en la base de los estudios filosóficos y humanísticos) es, como hemos indicado, el criterio de funcionalidad. Dado yuc la sintaxis estudia el funcionamiento del sistema morfológico, tendremos que basarnos, en un primer momento, en una sistematización de la morfología, pero sólo en cuanto a la función que cumplen los distintos elementos en el mensaje hablado o escrito.

En otras palabras, y como introducción a la sintaxis, presentaremos necesariamente una previa sistematización de la morfología. A la vez, puesto que la gramática no es autónoma e independiente del significado, sino que existe una estrecha vinculación entre semántica y sintaxis, tendremos que rener en cuenta, además, que un cambio de significación de una forma va unido a una estructura sintáctica diferente. ${ }^{?}$

El criterio de funcionalidad impulsado por el holandés Simón Dik en su obra Functional Grammar (1984), en la que expresara que el lenguaje no puede ser estudiado sin tener en cuenta su principal función, la comunicación humana $^{8}$, tuvo su correlato en el campo de las lenguas clásicas y, más específicamente en referencia a la lengua latina, con H. Pinkster. ${ }^{9}$

H. Pinkster estudia la sintaxis dentro del paradigma de la gramática funcional y especifica las relaciones funcionales en tres aspectos diferentes: funciones semánticas, funciones sintácticas y funciones pragmáticas. Estas últimas resultan las más adecuadas, pues están referidas al modo en que se utiliza el lenguaje en ciertas circunstancias que pueden modificar la interpretación del mensaje.

"Gramaticalización de la semántica: algunos hechos de lengua latina" en Cuadernos de Filología Clásica. Nueva Serie 2, 1992. pp. 103-110.

"La lengua es un instrumento social entre los seres humanos, usada con el objetivo primordial de establecer relaciones de comunicación entre hablantes y destinatarios" (Dik, S.C. TheTheory of functional Grammar, Berlín, Alemania. pag. 19)

9 PINKSTER, H. Semántica y sintaxis del latín. Ediciones clásicas. Madrid, España. 1995. 
En esta misma corriente, con ciertas particularidades, ubicamos los últimos estudios de Lisardo Rubio Fernánde $z^{10}$, latinista de larga trayectoria, en quien me inspiro para esta investigación y quien fue mi profesor universitario - "maestro" en el sentido clásico- - En sus últimas obras, Lisardo Rubio tiene un mayor acercamiento a las funciones pragmáticas del mensaje lingüistico, integrando de forma coherente elementos de distintas teorías.

En nuestro estudio tomaremos como base las cuatro categorías: Nombre, Adjetivo, Verbo y Adverbio. Las cuatro tienen un fundamento morfosintáctico y semántico, y con ellas podemos analizar los textos en las tres lenguas estudiadas. Las categorías "sobrantes" quedarán determinadas dé la siguiente manera:

- El artículo, del que carece el latín, lo consideraremos como una especie de adjetivo, modificador del sustantivo (expresando su género y número) y capaz de transformar una palabra (adjetivo, infinitivo, adverbio, etc.) en sustantivo; .

- Las preposiciones y conjunciones (excepto las conjunciones coordinadas, es decir, las que hacen realmente de "con-junción") no son más que partículas subordinantes que transforman (en el caso de las preposiciones) un sustantivo en adverbio o en adjetivo, o (en el caso de las conjunciones) una proposición subordinada en un sustantivo, adjetivo o adverbio, como veremos más adelante.

- El pronombre, como lo indica la misma palabra, está en lugar del nombre: entra, pues, en dicha categoría nominal.

- La interjección no es más que la irrupción emocional del hablante en la cadena del discurso. Es una inserción marginal en el organismo sintáctico, semejante al nombre en caso Vocativo.

De esta forma, operaremos para las tres lenguas con 4 categorías principales (nombre, adjetivo, verbo y adverbio) y con una serie de partículas

10 RUBIO FERNÁNDEZ, Lisardo. Nueva sintaxis latina simplificada. Ed. Ediclas. Madrid, España. (1995).Y también: Nociones básicas de gramática. El estudio de la gramática convertido en juego de mesa. Ediciones del Orto. Madrid, España. 1993. 
(preposiciones y conjunciones —exceptuadas las coordinadas-) que actuarán como "permutadores" capaces de efectuar traslados de una categoría funcional a otra.

Las posibilidades de expresión en base sólo a las cuatro categorías de palabras mencionadas serían escasas y muy pobres pero, con el instrumental de las partículas gramaticales, las posibilidades de expresión son casi infinitas.

\section{Cuestiones previas de terminología y significado}

1. Como primera cuestión previa, quiero referirme a la conjunción. La gramática tradicional engloba bajo este término las partículas subordinantes del verbo y las partículas coordinantes. En realidad, sólo las coordinantes son auténticas conjunciones, pues unen categorías o funciones semejantes. Como dice Lisardo Rubio", el mensaje de una auténtica conjunción es: "iSin novedad! Tan sólo más de lo mismo"; mientras que el de una partícula subordinante, sea preposición ante el nombre o conjunción de subordinación ante el verbo, es: "iAtención, hay novedad funcional!".

Por tanto, la coordinación (copulativa, disyuntiva o adversativa) marca una relación homofuncional de nivel jerárquico horizontal. La subordinación (conjunción de subordinación, incluido el pronombre relativo) marca una relación heterofuncional y de nivel jerárquico vertical.

2. En segundo lugar, las conjunciones de subordinación y las preposiciones son dos variantes de partículas subordinantes. Son el medio para efectuar traslados o cambios de categoría funcional. La conjunción de subordinación opera traslados del verbo; la preposición opera traslados del nombre. Las preposiciones hacen con los nombres la misma operación que las desinencias de los casos: subordinan el nombre a un verbo o a otro nombre.

11 RUBIO, Lisardo. Nueva Sintaxis Latina simplificada Ed. Ediciones Clásicas. Madrid. 1995, pág. 5. 
3. En tercer lugar, mantendremos como funciones sintácticas: la función nominal, la función verbal, la función adjetival (satélite del nombre) y la función adverbial (satélite del verbo) ${ }^{12}$. Sin embargo, no hay que identificar el nombre con la función nominal (sujeto o complemento directo), ni el verbo con la función predicativa (en relación con el sujeto), ni el adjetivo con la función adjetival (determinante del nombre), ni el adverbio con la función adverbial (determinante del verbo).

4. En cuarto lugar, al pronombre se le asigna la categoría del nombre (= está en lugar del nombre). Pero, dentro de los pronombres, el relativo es diferente por su complejidad: a la función de cualquier pronombre se le agréga el de llevar implícita una partícula subordinante verbal, dando lugar a la subordinación relativa. Además, como todo pronombre relativo tiene los factores de caso, género y número, tendremos que analizar su función en base al caso que posea, a la vez que introducirá una oración llamada subordinada relativa o adjetiva.

5. La primera gran diferencia que encontramos entre el castellano y el latín y griego (tomados ahora conjuntamente) es que la categoría palabra es inadecuada para expresar la unidad lingüística; lo es incluso en castellano, pero con mayor razón para el latín o griego que son lenguas de flexión.

Las verdaderas unidades lingüísticas son las unidades significativas (marcas de relaciones entre los términos que forman la cadena hablada o escrita). Tales marcas no son signos del código léxico sino del código gramatical, pero son signos con la característica de poseer las dos caras simultáneas: significante (objeto de estudio de la morfología, que se encarga de las "formas") y significado (objeto de estudio de la sintaxis, que se encarga de las conexiones entre los términos para integrarlos en la unidad superior que es la oración, y objeto de estudio también de la semántica).

12 En castellano, es corriente también el uso del adverbio modificando a un adjetivo (ej. extremadamente hermosa) pero en latín y griego una tal construcción sería anómala. 
6. Las palabras variables, tanto en castellano como en latín y griego (nombre — sustantivo y adjetivo—- pronombre, verbo y artículo, por más que este último sólo para el griego y castellano) poseen unidades significativas mínimas, llamadas monemas, que pueden ser de dos clases: monemas léxicos o lexemas y monemas gramaticales o morfemas. (El lexema es lo que tradicionalmente hemos llamado raíz, y el morfema equivaldría a lo que antes se conocía como "accidente" gramatical).

Los lexemas de una lengua hablada son ilimitados, y pueden seguir aumentando; no así en las lenguas consideradas "muertas" o cuyo estudio es sincrónico, limitado a un momento histórico. El número de los morfemas es limitado y cerrado para todas las lenguas, y ellos deben ser aprendidos para poder tener un manejo ágil de la lengua en cuestión

7. Las palabras invariables (adverbios, conjunciones, preposiciones e interjecciones) coinciden con el monema: monema léxico para las preposiciones e interjecciones; monema gramatical para las conjunciones. El caso de los adverbios es más ambiguo, ya que, para los adverbios de modo, en las tres lenguas estudiadas, podemos hablar de un monema léxicogramatical.

\section{Análisis de las cuatro categorías gramaticales básicas}

Nuestro objetivo básico en la enseñanza de las lenguas clásicas (latín y griego) radica en facilitar la interpretación (traducción) de textos que forman el patrimonio cultural y filosófico de nuestra cultura. Y nuestro gran obstáculo radica en la dificultad que hallamos en los alumnos para descubrir las conexiones entre los distintos términos que forman el mensaje. Las expresiones habituales ("no pude armar la frase", "tengo todas las palabras buscadas pero no puedo traducir la oración", "no sé qué hacer con tal infinitivo o participio", "me sobran acusativos", "no sé cómo ordenar la frase" etc), me han impulsado a seguir investigando para formular una sistematización morfosintáctica que permita ver la función que desempeñan los diferentes términos. 
Tanto el latín como el griego, por su rica flexión, pueden mantener libertades —en cuanto al orden de las palabras en la oración — que serían inadmisibles en castellano. Pero no por ello debemos dejar de reconocer que existen en las dos lenguas clásicas unas normas o tendencias referentes al "orden regular" que se resumen en los siguientes principios:

1. El sujeto encabeza la oración y el predicado verbal la cierra.

2. Todo elemento subordinado a otro lo precede inmediata o mediatamente.

3. Las partículas preceden inmediata o mediatamente al término que afectan para coordinarlo o subordinarlo.

Empecemos, pues, un análisis de las categorías antes mencionadas.

\section{Verbo:}

En las lenguas indoeuropeas, el verbo ocupa un lugar central en la oración gramatical. Al decir "central" no nos referimos al lugar que ocupa en la cadena hablada o escrita sino a su importancia como elemento aglutinador. En la órbita verbal, podemos tener el nombre en Nominativo, como sujeto o predicado nominal. Como complemento del verbo, podemos tener: el nombre en Dativo, como complemento indirecto; el nombre en Acusativo, como complemento directo; y el nombre en Ablativo (en el caso del latín), como complemento circunstancial. En el caso de que hubiese un nombre en Genitivo, ése sería complemento de otro nombre, es decir, conectará con algún satélite de la órbita verbal, como su determinación particular, o se conectará directamente con el verbo en casos especiales. Y si hubiera un Vocativo, éste se considera como una incrustación eventual en el discurso que sirve para llamar la atención de la persona (o cosa) a quien se dirige el hablante.

El verbo, en general, hace girar en torno a sí todos los casos y funciones. Pero su ubicación en la cadena hablada o escrita, en el caso del latín y griego, será normalmente al final de la oración como cerrando la frase y, a la vez, dominando desde su posición las funciones de los diferentes casos: el sujeto 
que encabeza la oración, y los complementos que están en su órbita. En castellano, el verbo suele ir después del sujeto.

Para que el verbo pueda cumplir su función de predicado verbal del sujeto debe tener generalmente las siguientes condiciones:

- aparecer en forma personal;

- no estar bajo la dependencia de ninguna partícula subordinante (conjunción de subordinación, pronombre relativo, o elemento introductor de una interrogativa indirecta).

Sin embargo, en el caso de oraciones subordinadas, llamadas completivas o sustantivas, en las lenguas latina y griega, el núcleo verbal podrá ir en Infinitivo, y su sujeto en Acusativo, pero dicho infinitivo como tal ya no cumple una función nominal, sino que es el núcleo verbal al interior de la subordinada, y es la oración subordinada entera la que cumplirá una función nominal. ${ }^{13}$

\section{Nombre:}

En latín y griego cumplen la función de nombre propiamente dicho los casos Nominativo y Acusativo con sus funciones predominantes de sujeto y complemento directo respectivamente. Algunos autores consideran el dativo con su función de complemento indirecto como nombre, aunque otros lo consideran como función adverbial. ${ }^{14}$

13. En latín y griego, considero que el Infinitivo cumple función verbal de una oración subordinada cuando tiene sujeto propio en acusativo. Y considero que cumple función nominal cuando no tiene sujeto propio y actúa como sujeto u objeto directo de la oración principal. Por ello distingo en los ejemplos de la función nominal, de la segunda parte, entre "Infinitivo" ( $\sin$ sujeto propio) y "Oración de Infinitivo" (con sujeto propio).

14. Algunos latinistas, como Lisardo Rubio Fernández, consideran el dativo como función adverbial cuyo valor es siempre el de la persona, o eventualmente cosa, que resulta interesada, beneficiada o perjudicada en el proceso indicado en la oración. Todas las clases de dativo que presentan las gramáticas tradicionales se reducen a la noción general de "interés". Cf. Lisardo Rubio Fernández y Tomás 
El caso del Genitivo que traducimos con un "de", en la mayoría de casos es complemento del nombre, $y$ por ello determina al nombre, cumpliendo así la función propia del adjetivo (ej. domus patris = casa del padre, casa paterna); eso es igual en latín que en griego. (En el caso del griego, cuando el genitivo, va regido de preposición, pasa automáticamente a tener valor circunstancial, o sea, una función adverbial). Hay casos en latín y griego en que el propio verbo requiere necesariamente el régimen de genitivo (los verbos de "memoria", por ejemplo, que curiosamente coinciden con el "acordarse de" castellano que usa la preposición "de"). En tales casos el genitivo pierde su función de complemento del sustantivo y se convierten en categoría funcional de adverbio.

En el caso del complemento circunstancial de modo, Dativo en griego y Ablativo en latín, el sustantivo pasa a la categoría funcional de adverbio sin que intervenga para ello una preposición. Igualmente tienen función adverbial los nombres o sustantivos en los casos Genitivo, Acusativo y Dativo griegos precedidos de preposición, y el Acusativo y Ablativo latinos precedidos de . preposición.

Dicho de otra manera: cualquier preposición (en latín, las preposiciones sólo pueden regir sustantivos en Acusativo o Ablativo; en griego, pueden regir sustantivos en caso Genitivo, Acusativo y Dativo) transforma la categoría de nombre a la de adverbio, es decir, traslada la función del nombre a la función de adverbio. Aparece claramente el papel de "permutador" de la preposición.

González Rolán. Nueva Gramática Latina Ed. Coloquio Editorial, 1990. Madrid, España. \& 257-268. (En este sentido, el dativo podría ser considerado analógicamente como un complemento circunstancial de modo, es decir, con función adverbial). 
Adjetivo:

Cumple la función de determinar de alguna manera al nombre. Los adjetivos cumplen, pues, la función adjetival, satélite del nombre. Sin embargo, otras palabras pueden cumplir esta misma función:

- un nombre en caso genitivo (en latín y griego); en castellano equivale al nombre precedido de la preposición "de". El caso genitivo, en las lenguas clásicas citadas es un gran recurso para la creación de adjetivos funcionales.

- un nombre en aposición: ej. la ciudad Roma, o la ciudad de Roma, o la ciudad romana.

- un nombre en ablativo en latín, con o sin preposición, utilizado para determinar a otro nombre (iuvenis magno nomine, joven de ilustre nombre; o bien lex de reputendis: ley de desfalcos).

También cumple la función adjetiva una oración introducida por un pronombre relativo, siempre que éste determine a un nombre antecedente. Esto ocurre en las tres lenguas. El modo del verbo de la llamada oración subordinada relativa va en Indicativo ya que su función es determinar algo expresado como real. El cambio del Indicativo a otro modo verbal en la subordinada relativa implica un cambio semántico y de función. Es distinto decir "envió un embajador que contó los futuros proyectos", a decir "envió un embajador que contara los futuros proyectos". En el segundo caso, el relativo tiene una función adverbial final equivalente a "para que contara". Esto ocurre en las tres lenguas que analizamos. Además, hay que tener bien en claro que una oración de relativo no se subordina a la oración principal en su conjunto, sino exclusivamente al elemento de la oración principal llamado antecedente.

\section{Adverbio:}

Las lenguas analizadas tienen sus propios adverbios, como formas no flexivas, carentes de declinación, género y número. En castellano, sin embargo, algunos adverbios pueden experimentar variación formal al admitir 
el grado superlativo o al combinarse con sufijos diminutivos (ej. prontísimo, o cerquita, respectivamente).

Aparte de estas formas adverbiales propias, el latín y griego disponen de casos (ablativo en latín, y dativo y genitivo en griego) que, sin estar precedidos de preposición, operan como complementos circunstanciales (o sea, adverbios funcionales) de modo, extensión en el espacio y tiempo, según el contexto.

Sin embargo, lo más abundante y operativo son las preposiciones griegas y latinas que convierten un sustantivo en adverbio. En latín y griego los complementos circunstanciales pueden operar con preposición + nombre (en genitivo, dativo o acusativo en el caso del griego; y en acusativo y ablativo en el caso del latín). En castellano abundan los ejemplos de las llamadas "frases preposicionales" en las que la preposición unida a la palabra regida por ella adquiere un valor adverbial. El adverbio resultante de tales sintagmas no está ni en la preposición ni en el nombre regido por ella, sino en la unidad integrada por preposición + nombre.

Igualmente, podemos reconocer adverbios funcionales en las lenguas latina y griega en la conjunción de subordinación + verbo. Son las llamadas oraciones subordinadas adverbiales o circunstanciales, ya que la expresión "circunstancial" es lo propio de la categoría gramatical llamada adverbio. Éstas pueden ser, según la clasificación coincidente en las tres lenguas estudiadas: finales, temporales, causales, consecutivas, concesivas, condicionales, comparativas y modales.

No debemos confundir la categoría de palabras mencionadas (verbo, nombre, adjetivo, adverbio) con la función (verbal, nominal, adjetival y adverbial) respectivamente. Sería como si en el organismo animal no distinguiéramos los órganos de sus funciones; por ejemplo, los pulmones de su función respiratoria, el estómago de su función digestiva, etc. Y, si bien en el organismo animal tal confusión no tendría graves consecuencias, en la oración gramatical, sí la tendría, pues lo que llamamos "función sintáctica" no está reducida y ligada, como hemos visto, a una sola categoría de palabras. 
Así, podemos decir que el verbo es el órgano de la función predicativa; d nombre es el órgano de la función nominal; el adjetivo es el órgano de la linción adjetival; y el adverbio es el órgano de la función adverbial. Pero la función sintáctica no queda reducida a una sola categoría de palabras, sino que podemos encontrar la función predicativa sin verbos morfológicos, la función nominal sin nombres morfológicos, la función adjetival sin adjetivos morfológicos y la función adverbial sin adverbios morfológicos.

Las cuatro categorías de palabras mencionadas - nombre, adjetivo, verbo y adverbio- forman el marco básico de donde saldrán los elementos para la construcción de cualquier mensaje lingüístico tanto en castellano como en latín y griego. El siguiente esquema sintetiza las funciones sintácticas y sus realizaciones morfológicas.

\section{SEGUNDA PARTE}

Análisis Morfosintáctico Funcional de Textos

\begin{tabular}{|c|c|c|}
\hline $\begin{array}{l}\text { FUNCIONES } \\
\text { SINTÁCTICAS }\end{array}$ & \multicolumn{2}{|c|}{ POSIBLES REALIZACIONES MORFOLÓGICAS } \\
\hline Función VERBAL & \multicolumn{2}{|c|}{ VERBO (es el predicado normal) } \\
\hline & $\begin{array}{l}\text { Realizaciones según } \\
\text { clases de palabras }\end{array}$ & $\begin{array}{l}\text { Realizaciones } \\
\text { «oracionales» }\end{array}$ \\
\hline $\begin{array}{l}\text { Función } \\
\text { NOMINAL } \\
\text { (sujeto; } \\
\text { complemento } \\
\text { directo) }\end{array}$ & $\begin{array}{l}\text { a) NOMBRE } \\
\text { b) Pronombre } \\
\text { c) Adjetivo } \\
\text { sustantivado } \\
\text { d) Infinitivo } \\
\text { e) Participio (gr.) } \\
\text { (a), (b), (c) en caso } \\
\text { Nominativo o } \\
\text { Acusativo, en latín y } \\
\text { griego, para sujeto o } \\
\text { complemento directo } \\
\text { respectivamente }\end{array}$ & $\begin{array}{l}\text { f) Oración de infinitivo } \\
\text { g) Oración sustantiva } \\
\text { h) Oración relativa } \\
\text { sustantivada } \\
\text { i) Oración interrogativa } \\
\text { indirecta } \\
\text { j) Oración de participio } \\
\text { (gr.) }\end{array}$ \\
\hline
\end{tabular}

B. APL 42(42), 2006 


\begin{tabular}{|c|c|c|}
\hline $\begin{array}{l}\text { Función } \\
\text { ADJETIVAL }\end{array}$ & $\begin{array}{l}\text { a) ADJETIVO } \\
\text { b) . Nombre precedido } \\
\text { de de (cast.) } \\
\text {. Nombre en genitivo } \\
\text { (lat. / gr.) } \\
\text {. Nombre como } \\
\text { aposición } \\
\text {. Nombre en ablativo } \\
\text { con o sin } \\
\text { preposición (lat.) } \\
\text { Nombre en dativo } \\
\text { (gr.) }\end{array}$ & $\begin{array}{l}\text { c) Oración de relativo con } \\
\text { antecedente } \\
\text { d) Oración de participio } \\
\text { (gr.) }\end{array}$ \\
\hline $\begin{array}{l}\text { Función } \\
\text { ADVERBIAL }\end{array}$ & $\begin{array}{l}\text { a) ADVERBIO } \\
\text { b) Nombre, pronombre } \\
\text { o adjetivo } \\
\text { sustantivado con } \\
\text { preposición } \\
\text { c) Sustantivo sin } \\
\text { preposición (latín y } \\
\text { griego) }\end{array}$ & $\begin{array}{l}\text { d) Oraciones subord. } \\
\text { adverbiales: } \\
\text { - temporales, } \\
\text { - finales, } \\
\text { - causales, } \\
\text { - concesivas, } \\
\text { - consecutivas, } \\
\text { - condicionales, } \\
\text { - comparativas. }\end{array}$ \\
\hline
\end{tabular}

* En el esquema presentado se indica cuando las realizaciones son propias de una o dos de las lenguas; cuando no hay indicación, es que las realizaciones son comunes a las tres lenguas.

Para una mayor claridad, seguiremos con ejemplos el orden del esquema presentado. Hemos elegido ejemplos sencillos de los discursos o antologías más usados en los cursos de aprendizaje para que puedan ser reconocidos fácilmente por los estudiantes. Hemos señalado en color lo específico en cada caso.

FUNCIÓN VERBAL es la de predicado del sujeto gramatical

1) Cumple esta función el VERBO, siempre que se den las siguientes condiciones: 
- que esté en forma personal, y

- que no esté introducido por alguna partícula subordinante (conjunción de subordinación, pronombre relativo o elemento introductor de la interrogación indirecta)

Ejemplos: Cast. César soltó las naves

Lat. Caesar naves solvit (César soltó las naves) extranjeros)

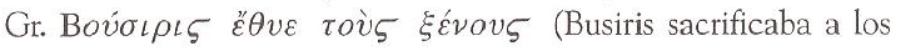

2) La función predicativa puede tomar forma de Predicado Nominal, el cual puede tener las siguientes formas:

- Verbo ser (sum, en latín; eilmi, en griego) + nombre o adjetivo.

En este caso el verbo ser pierde su valor semántico y sólo expresa el modo, tiempo, persona y número.

Cast.: Antonio es cantor.

Lat.: Petrus erat rector. (Pedro era rector)

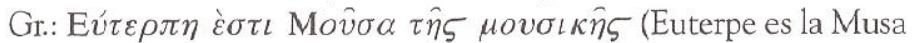
de la música)

- Predicación nominal pura, donde se omite el verbo copulativo ser:

Cas.: El mejor alcalde, el rey

Lat.: Maximus magíster, populus (El mayor maestro, el pueblo)

Gr. X $\alpha \lambda \varepsilon \pi \grave{\alpha}$ ( ) $\tau \grave{\alpha} \kappa \alpha \lambda \grave{\alpha}$. (Las cosas bellas (son) difíciles)

- En la predicación nominal, el nombre puede ser sustituido por los nombres funcionales ${ }^{15}$, tales como:

15 Ver más abajo los nombres funcionales, o posibles suplencias nominales. Aquí sólo señalamos aquellas que pueden sustituir a un nombre en su función secundaria de predicado nominal. 
* Una oración entera como predicado nominal:

Cast. El final del discurso fue que él tomaba las armas

Lat.: Ultimum orationis fuit se arma capere

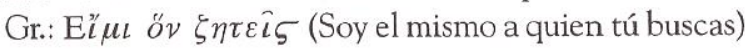

* Un infinitivo, como forma nominal del verbo:

Cas.: El final del discurso fue huir

Lat.: Ultimun orationis fuit fugere

Nota: En latín se da además el caso de función predicativa, el llamado Infinitivo histórico, que no es sino un infinitivo que actúa como Predicado de un sujeto de cualquier número y persona. Es un recurso estilístico y que le ahorra al autor el señalar los morfemas gramaticales propios del verbo. En castellano tenemos un ejemplo en los hablantes de otras lenguas que al empezar a hablar castellano usan el infinitivo sin reparar en tiempos, número ni persona.

FUNCIÓN NOMINAL: es la que corresponde al sujeto y al complemento directo.

Tratándose del sujeto, pueden cumplir esta función los siguientes elementos gramaticales (las cuatro categorías dichas y ciertas oraciones):

a) NOMBRE:

Cast.: Los enemigos combatieron.

Lat.: Exercitus rediit (el ejército regresó)

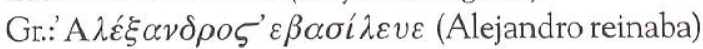

b) PRONOMBRE:

Cast.: Ellos combatieron

Lat.: Is rediit (él regresó)

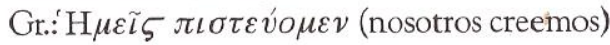

c) ADJETIVO:

Cast.: Los buenos permanecen

Lat.: Sapientes redeunt (los sabios regresan)

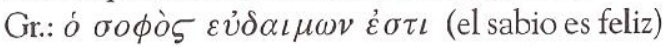


d) INFINITIVO:

Cast. Regresar es bueno

Lat.: Ridere bonum est (reír es bueno)

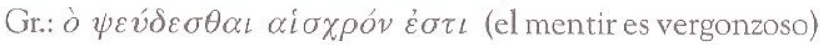

e) PARTICIPIO:

Gr.: $\mu \iota \sigma \hat{\omega} \nu \mu \iota \sigma \varepsilon \imath \hat{\tau} \alpha \iota$ (el que odia es odiado)

f) ORACIÓN DE INFINITIVO:

Lat:: Traditum est Homerum caecum fuisse (Es tradición que Homero fue ciego)

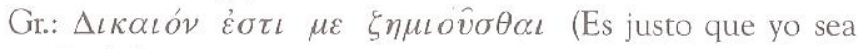
castigado)

g) ORACIÓN COMPLETIVA SUSTANTIVA:

Lat.: $Ф\llcorner\varepsilon \rho \iota \pi o \tau \varepsilon \sigma \tau v \tau \varepsilon \rho \rho \varepsilon \mu$ (Es posible que yo me equivoque)

h) ORACIÓN RELATIVA SUSTANTIVADA:

Lat.: Qui hostem feriet, mihi erit Carthaginensis (Quien hiera al enemigo será para mí un cartaginés)

G.: $\zeta \tau \alpha \hat{v} \tau \alpha \lambda \dot{\varepsilon} \gamma \varepsilon \iota$ $\psi \varepsilon v ́ \delta \varepsilon \tau \alpha \iota$ (Elque dice estas cosas, miente)

i) ORACIÓN INTERROGATIVA INDIRECTA:

Lat.: Quaeritur sintne dii, necne sint (Que haya dioses o no los haya es cuestionable)

j) ORACIÓNDE PARTICIPIO:

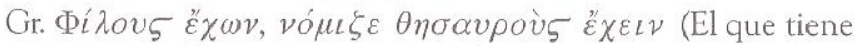
amigos, considere que tiene tesoros) 
Tratándose del complemento directo, pueden cumplir esta función los siguientes elementos gramaticales:

a) NOMBRE:

Cast.: El río lleva agua

Lat.: Manus manum lavat (Una mano lava la otra)

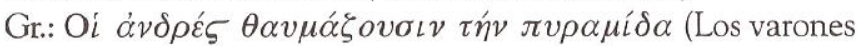
admiran la pirámide)

b) PRONOMBRE:

Cas.: Ellos me miran

Lat. Imperator suos laudat (el emperador alaba a los suyos)

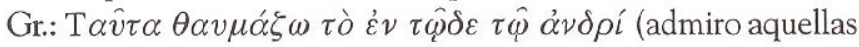
cosas en este hombre)

c) ADJETIVO:

Cast.: Desea siempre lo bueno

Lat.: Bona sperare non oportet (No conviene esperar cosas buenas)

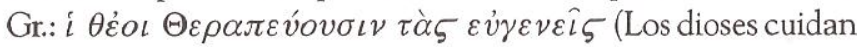
a los nobles)

d) INFINITIVO:

Cas.: Quiero volver a tu lado

Lat.: Vincere scis (Sabes vencer)

Gr. $\Delta \varepsilon \dot{\varepsilon} \rho \alpha \iota \dot{v} \mu \hat{\omega} v \mu \eta \dot{\eta} \theta o \rho v \beta \varepsilon \tilde{\imath} v$ (les pido no alborotarse)

e) PARTICIPIO:

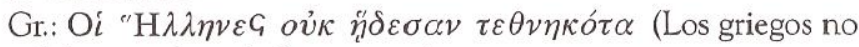
celebraron al que había muerto)

f) ORACIÓN DE INFINITIVO:

Lat.: Credo Deum esse sanctus (Creo que Dios es santo)

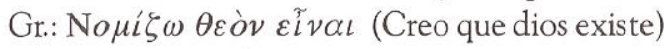


g) ORACIÓN SUSTANTIVA:

Cast.: Veo que estás muy preocupado

Lat.: Opto ut beatus sis (Deseo que seas feliz)

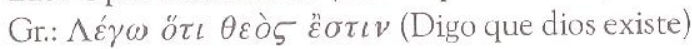

h) ORACIÓN RELATIVA SUSTANTIVADA:

Cast.: Aprobaré a los que estudien en serio

Lat.: Fortuna vindicat quod dedit (La fortuna reclama lo que ha concedido)

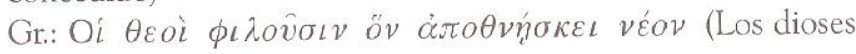
aman al que muere joven)

i) INTERROGATIVA INDIRECTA:

Cas.: No sé qué piensan ustedes

Lat.: Quaero quis venerit (Pregunto quién ha venido)

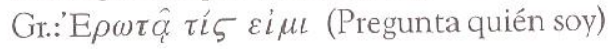

j) ORACIÓNDE PARTICIPIO:

Gr. Oí $\delta \alpha \theta \varepsilon o ̀ v o ̛ v \tau \alpha$ (Sé que dios existe)

FUNCIÓN ADJETIVAL: consiste en determinar de alguna manera al nombre. Podemos considerarlo como satélite del nombre. El adjetivo (morfológico) es el que primariamente ejerce tal función.

Cumplen función adjetiva:

a) ADJETIVO:

Cast.: Los buenos amigos son un tesoro.

Lat.: Multae insulae parvae sunt (Muchas islas son pequeñas)

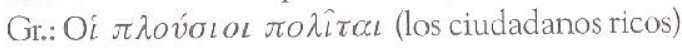

b) NOMBRE:

- nombre precedido de "de" (sólo en castellano)

Cast.: Hombre de empresa

B. APL 42(42), 2006 
- nombre en Genitivo (latín y griego)

Lat.: Domus patri (la casa del padre $=$ la casa paterna)

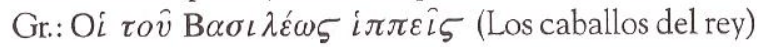

- nombre como Aposición

Cast. : Atenas, capital de Grecia

Lat. : Cicero cónsul Romam servavit (Cicerón —en calidad de— cónsul salvó a Roma)

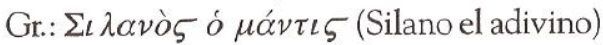

- nombre en Ablativo con o sin preposición (latín)

Lat:: Iuvenis magno nomine (joven de gran nombre)

Lat.: Lex de repetundis (la ley de desfalcos)

- nombre en dativo (griego)

Gr.: 'O $\pi \dot{\alpha} \pi \pi \circ \varsigma \mu \circ \iota \dot{\alpha} \pi \varepsilon \dot{\varepsilon} \theta \alpha \varepsilon$ (Mi abuelo ha muerto)

c) ORACIÓN DE RELATIVO con antecedente:

Cast.: Tomó el camino que conducía a la ciudad.

Lat.: Pecuniam quam credidisti reddo (Te devuelvo el dinero que me prestaste).

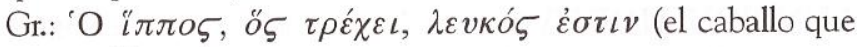
corre es blanco)

d) ORACIÓN DEPARTICIPIO (griego)

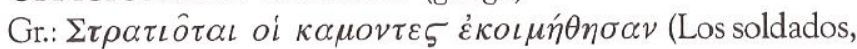
que estaban fatigados se acostaron)

FUNCIÓN ADVERBIAL: como determinante del verbo. El adverbio propiamente dicho es el "órgano" de la función adverbial. Sin embargo, además de los adverbios morfológicos, y de los nombres o adjetivos precedidos de preposición - para el griego y el latín — existen numerosas formas para crear funciones adverbiales a través de las conjunciones de subordinación más el verbo. 
Cumplen, pues, función adverbial:
a) ADVERBIO:

Cast.: Salió apresuradamente

Lat.: Homo sapiens vivit beate (el hombre sabio vive felizmente)

Gr.: $\alpha \dot{v} \theta \rho \omega \pi o_{\zeta} \theta \varepsilon \dot{\imath} \chi \alpha \lambda \varepsilon \pi \hat{\omega} \zeta$ (el hombre corre difícilmente)

\section{b) NOMBRE CON PREPOSICIÓN: ${ }^{16}$}

Cast.: Pasé por la casa

Lat.: Ad Capuam profectus sum (Fui hacia Capua)

Gr.: $v \tau \hat{n} \dot{\alpha} \gamma o \rho \hat{\alpha}$ eioı $v$ oikía (en la plaza hay casas)

\section{c) NOMBRE SIN PREPOSICIÓN:}

Tanto en latín como en griego se dan numerosos sustantivos solos, sin preposición, que pueden tener una función adverbial: trataremos de analizar separadamente las formas latinas y las griegas. En castellano, en cambio, son muy pocos y hacen únicamente referencia al tiempo y a la cantidad. Ej. una vez, en la selva...; el pasado año salimos de paseo...; el próximo verano saldremos al campo; pesaba cinco quilos; permaneció cinco días en el campamento etc..

\section{- Formas latinas}

\section{caso Acusativo}

* Con verbos de movimiento, indicando dirección y tratándose de nombres propios de ciudades o islas menores y con los nombre domus (casa) y rus (campo)

Ej. Eo domum (voy a casa)

\footnotetext{
16 En latín sólo pueden regir preposición el caso Acusativo y el caso Ablativo. En griego pueden regir preposición los casos Acusativo, Genitivo y Dativo. En todos estos casos, se trata de adverbios funcionales.
} 
* Indicando la extensión en el espacio y tiempo

Ej. Hasta sex pedes longa " (lanza de seis pies de larga)

Ej. Pugnatum est quinque horas ( se luchó durante cinco horas)

* Algunos nombres neutros en acusativo equivalen a adverbios

Ej. magnam partem (en gran parte); id temporis (entonces); nihil (de ningún modo)

\section{caso Genitivo}

* Con verbos que significan apreciar, valer, estimar... el genitivo cumple una función adverbial.

Ej. omnes te magni faciunt (todos te tienen en gran estima)

*Los verbos judiciales tales como absolver, acusar etc. Rigen un genitivo con valor adverbial traición)

Ej. Miltiades proditionis accusatus est (Milcíades fue acusado de

\section{caso Ablativo}

* Para indicar el lugar de dónde con nombres propios de ciudades e islas pequeñas ylas palabras domus (casa) y rus (campo)

Ej. Domo venio (vengo de casa)

Ej. Redeo Athenis (regreso de Atenas)

* Un caso especial lo forma el sintagma formado por participio en ablativo sin preposición y un sustantivo concordando en caso, género y número. La gramática tradicional latina lo ha llamado "ablativo absoluto", como si se tratara de una construcción independiente. En realidad, tanto en el texto latino como en la traducción, esta construcción de participio + suatantivo en ablativo están conectados con la oración principal.

$\mathrm{Ej}$. duce vulnerato omnes fugerunt (herido el caudillo, todos huyeron)

Este ablativo expresa simultáneamente una circunstancia temporalcausal. 


\section{- Formas griegas}

\section{caso Acusativo}

* El llamado Acusativo de relación, que responde a las preguntas: ¿en cuanto a qué?, ibajo que punto de vista?, ien qué parte?

Ej. $\tau \dot{\eta} v \kappa \varepsilon \phi \alpha \lambda \dot{\eta} v \dot{\alpha} \lambda \gamma \varepsilon \varepsilon \dot{i}$ (tiene dolor de cabeza)

* El llamado Acusativo de extensión, que expresa distancia en el espacio o duración en el tiempo. Responde a la pregunta ¿cuánto?

Ej. $\dot{\varepsilon} v \tau \alpha \hat{v} \theta \alpha \dot{\varepsilon} \mu \varepsilon\llcorner v \varepsilon v \dot{\eta} \mu \dot{\varepsilon} \rho \alpha \zeta \dot{\varepsilon} \pi \tau \dot{\alpha}$ (permaneció allí siete días).

* Los acusativos de nombres o adjetivos, antiguos acusativos internos,: (en adelante)

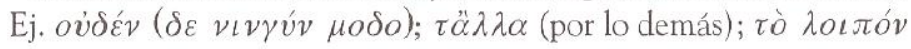

\section{caso Genitivo}

* Indicando el precio o aprecio que se tiene en algo



* Indicando la parte por la que se toma algo Ej. $\check{\varepsilon} \lambda \alpha \beta o ́ v \mu \varepsilon \tau \hat{\eta} \zeta \zeta \omega ́ v \eta \zeta$ (me tomaron por la cintura)

* Indicando causa, responde a la pregunta la causa de qué?

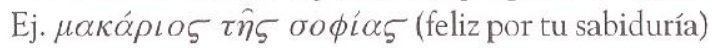

* Indicando el delito, crimen o acusación en verbos judiciales Ej. $\dot{\alpha} \pi \circ \phi \varepsilon v \dot{\gamma} \varepsilon \iota \nu \kappa \lambda \circ \pi \hat{\eta} \zeta$ (ser absuelto de robo)

* Indicando separación, alejamiento, punto de partida Ej. $\pi \alpha \dot{v} \varepsilon \iota v \tau \iota v \alpha \grave{\alpha} \hat{\eta} \varsigma \dot{\alpha} \rho \chi \hat{\eta} \varsigma$ (cesar a uno de su mando)

* Equivalente al llamado "Ablativo absoluto" latino, existe el "Genitivo absoluto" griego. Se trata de un participio en caso Genitivo, sin preposición, 
concordando con un sustantivo en caso, género y número ${ }^{17}$. Actúa como adverbio funcional y expresa causa, tiempo, y/o modo.

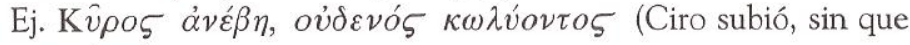
nadie se opusiera)

\section{caso Dativo}

* Indicando el medio o instrumento de una acción

Ej. ó $\hat{\omega} \mu \varepsilon v \tau o \hat{i} \varsigma \dot{o} \phi \theta \alpha \lambda \mu o \hat{\imath} \varsigma$ (vemos con los ojos)

* Indicando la causa eficiente de un efecto

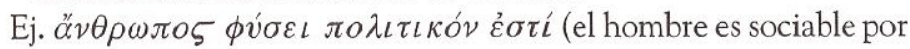
naturaleza)

* Indicando la cantidad en que una cosa se diferencia de otra

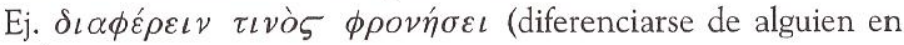
prudencia)

* Indicando el modo o circunstancias concomitantes de una acción

Ej. $\sigma \iota \gamma \hat{\eta}(\varepsilon v \quad \sigma \iota \lambda \varepsilon v \chi \iota 0) ; \beta \iota \alpha(\alpha \lambda \alpha \phi v \varepsilon \rho \xi \alpha) ; i \delta i \alpha$ (particularmente); $\lambda o ́ \gamma \omega$ (de palabra) etc.

* Indicando el tiempo con los nombres de día, mes y año acompañados de un ordinal y con los nombres de fiestas

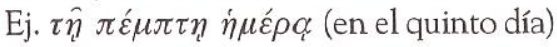

Todos los ejemplos señalados de nombre sin preposición en función de adverbio no tienen su correspondencia en castellano. Dicha lengua precisa siempre de alguna preposición, salvo en los casos que indican tiempo y cantidad, como expresamos anteriormente.

17 Cuando el participio es el verbo "ser", en griego se expresa, a diferencia del latín

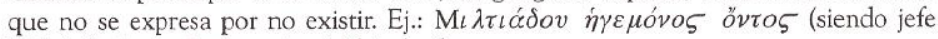
Milcíades); en latín sería: Miltiade duce. 


\section{d) ORACIONES SUBORDINADAS ADVERBIALES:}

Son muy numerosas y generalmente se les llama oraciones subordinadas adverbiales o circunstanciales, ya que expresan la circunstancia, lo cual es propio de la categoría gramatical llamada adverbio. De la misma manera que, en el párrafo b), vimos cómo una preposición más sustantivo se convertía en un adverbio funcional, podemos apreciar ahora que una partícula o "conjunción subordinante" + verbo se convierte en adverbio funcional bajo el nombre de subordinación adverbial o circunstancial. Estas oraciones subordinadas adverbiales pueden ser: temporales, finales, causales, concesivas, consecutivas, condicionales y comparativas.

\section{* temporales}

encabezadas por partículas (en castellano adverbios) o conjunciones expresando la circunstancia de tiempo: cuando, antes que, después que, mientras que, hasta que etc.

- Cast. Iré cuando tú hayas regresado

- Lat: Cum Caesar in Galliam venit, ibi duae facciones erant (cuando César vino a la Galía, había allí dos partidos) ${ }^{18}$

- Gr.: ö $\tau \varepsilon \delta \dot{\varepsilon} \tau \alpha \hat{v} \tau \alpha \tilde{\eta} \nu, \tilde{\eta} \sigma \alpha \nu \mu \varepsilon \dot{\sigma} \sigma \alpha \iota v \dot{\gamma} \chi \tau \varepsilon \zeta$ (cuando eso ocurría, era media noche)

\section{* finales}

encabezadas por partículas o conjunciones expresando finalidad, intención, propósito: para que, a fin de que, etc.

18 Obsérvese que cum con valor de "cuando" debe regir el verbo en modo Indicativo (venit). Si el verbo está en modo subjuntivo, el valor temporal de cum se combina con un matiz causal. Es el llamado cum histórico, muy frecuente en narraciones latinas, que puede traducirse en castellano por como + verbo en subjuntivo o bien por gerundio, simple o compuesto según el verbo latino esté en Imperfecto de Subjuntivo o Pluscuamperfecto de Subjuntivo respectivamente. Ej: C. Marius, cum omnes portus terrasque fugeret, in Africam pervenit (huyendo C. Mario de todos los puertos y detonas las tierras, llegó a Africa). 
- Cast.: Iré para que tú estés contento

- Lat.: Germani eo consilio Rhenum transierunt, ut Galliam occuparent (los germanos atravesaron el Rin para invadir la Galia)

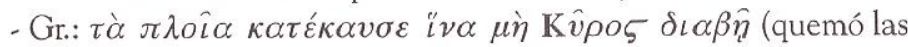
naves para que no pasase Ciro)

\section{* causales}

encabezadas por una partícula o conjunción expresando causa: porque, ya que, puesto que, etc.

Cast.: Me iré, porque asílo deseas

Lat.: Dux milites pro castris collocavit, quod hostes appropinquabant (el general dispuso los soldados ante el campamento, porque los enemigos se acercaban) marcho)

Gr.: $\dot{\varepsilon} \pi \varepsilon \iota \delta \dot{\eta} \dot{\varepsilon} \pi \iota \theta v \mu \varepsilon \hat{\imath} \zeta$, $\alpha \dot{\kappa} \varepsilon \dot{\rho} \propto \mu \alpha \iota$ (puesto que lo deseas, me

\section{* concesivas}

encabezadas por partículas o conjunciones, expresando que, a pesar de la objeción presentada, no se invalida lo expresado en la oración principal .

Cast.: Aunque llueva, iré

Lat.:quamvis dives sis, beatus non es (aunque seas rico, no eres feliz) Gr.: $\kappa \alpha i ́ \pi \varepsilon \rho \beta \alpha \sigma\llcorner\lambda \varepsilon \grave{v} \varsigma \ddot{\omega} v, \ddot{\alpha} \kappa o v \sigma o v$ (aunque seas rey, escucha)

\section{* consecutivas}

encabezadas por una partícula o conjunción que precisa de una correlación en la oración principal para que su sentido sea la consecuencia de de aquella.

Cast. Me suplicó con tanta insistencia, que no pude negarme

Lat:: Nullus liber est tam malus, ut non aliqua parte prosit (ningún libro es tan malo que no aproveche en algún sentido)

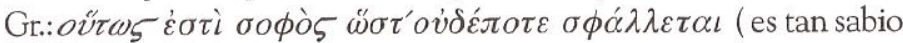
que nunca se equivoca) 
Sólo en griego, cuando la consecuencia se considera posible, pero no indica si se realizará o no, se construye con infinitivo y la negación en tal caso es $\mu \eta$ :

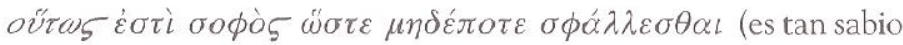
que no puede equivocarse nunca; o es tan sabio como para no equivocarse nunca).

\section{* condicionales}

encabezadas por partículas o conjunciones que formulan una premisa sin cuyo cumplimiento no sería válido el contenido de la oración principal. La partícula más usual en castellano es $s i$

Cast.: Si tengo un amigo, soy feliz

Lat.: Si amicum habeo, felix sum (si tengo un amigo, soy feliz)

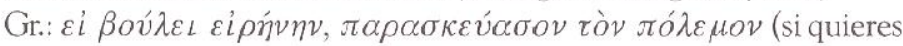
la paz, prepara la guerra)

\section{* comparativas}

encabezadas por partículas que comparan la oración subordinada frente a la principal. Al igual que las subordinadas consecutivas, en latín y griego precisan de un término correlativo en la principal. En castellano no es imprescindible.

Cast.: Como te anunciamos, venimos a visitarte.

Lat.: Erat talis qualis esse oportebat (era tal como convenía que fuera)

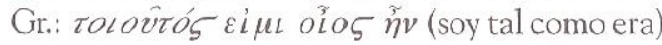

Los ejemplos de la lengua griega y latina, presentados en esta parte segunda, han sido elegidos de los textos de gramática de las lenguas clásicas, de uso general, y responden todos ellos a oraciones simples, no complejas. El mismo método usado para analizar tales oraciones podría utilizarse para textos más complejos donde es elevado el número de las llamadas oraciones subordinadas. La metodología de análisis sería la misma, considerando que las preposiciones y las conjunciones de subordinación tienen el mismo 
contenido: trasladar el nombre o el verbo respectivamente a funciones que en principio no corresponden a su esencia morfológica, y convertirlos en sustantivos, adjetivos o adverbios "funcionales".

La selección de textos complejos, latinos y griegos, con su análisis funcional correspondiente queda para un futuro trabajo.

\section{Consideraciones Finales}

1) Actualmente, en nuestro país, los estudiantes de latín y/o griego son generalmente universitarios que siguen cursos en las áreas de humanidades, relacionadas con la literatura, comunicación, filosofía o lingüística. Es urgente hacerles tomar conciencia de la necesidad de ejercer un razonamiento lógico y académico sobre la lengua propia, señalando las coincidencias y las diferencias respecto a las lenguas clásicas, de las que el castellano ha heredado gran parte de su estructura.

2) Conviene que el estudio gramatical sobre textos latinos y griegos integre desde el inicio el aspecto funcional-semántico, el cual deberá apoyarse sobre la base morfológica o morfosintáctica presentada durante los años de enseñanza primaria y secundaria, superando las deficiencias o ambigüedades que se hayan presentado a lo largo del proceso de los correspondientes aprendizajes.

3) Ante la abundante proliferación de terminologías para las distintas categorías gramaticales, considero válido y eficaz tomar en cuenta las cuatro categorías básicas de nombre, adjetivo, verbo y adverbio, con sus funciones respectivas. A la vez, urge reconocer que dichas funciones pueden ser desempeñadas por otros mecanismos mediante el uso de preposiciones o conjunciones, partículas que transforman los nombres o los verbos en sustantivos, adjetivos o adverbios "funcionales".

4) Sería recomendable buscar los medios para incursionar en los currícula de lengua, correspondientes a los niveles de enseñanza primaria y secundaria, a fin de que los profesores delárea de lengua y gramática puedan 
iniciar con los alumnos un razonamiento gramatical que les haga captar la diferencia existente entre la clase de una palabra y su función.

5) Poder reconocer lo que hay de común en la estructura de las lenguas castellana, latina y griega, es decir, poder captar con mayor facilidad y claridad las características distintivas y originales de sendas lenguas, representaría un avance invalorable para la interpretación y traducción de textos clásicos que están en la base de los estudios humanísticos.

6) La interpretación y traducción de textos clásicos es una tarea que exige rigor en el análisis funcional de las oraciones del texto de origen y, a la vez, exige un amplio conocimiento de la lengua a la que se traduce. Supone reconocer las características propias de cada lengua, respetar la estructura original cuando la propia lengua lo permita, rechazar los "calcos" fáciles y captar la esencia semántica que encierran los términos latinos y/o griegos.

7) Si la práctica del análisis siempre rinde sus frutos en cualquier espacio de la vida académica, los esfuerzos analíticos aplicados al terreno gramatical resultan sumamente beneficiosos para todo estudiante. En efecto, obligan a ascender hasta grados de abstracción, cuya insospechada existencia producirá particular disfrute, en un campo que es común a todo ciudadano: su lengua materna. El esfuerzo que este análisis comporta será recompensado en forma adicional cuando se trate de un ciudadano de cultura avanzada que sea capaz de incursionar en lenguas ajenas y establecer algún tipo de comparación entre éstas y la propia.

\section{BIBLIOGRAFÍA}

ALARCOS LLORACH, E. Gramática de la lengua española. Ed. EspasaCalpe. Madrid. 1994.

ALFAGEME, Ignacio R. Nueva Gramática Griega. Ed. Coloquio. Madrid.

BASSOLS DE CLIMENT, Mariano. Sintaxis latina. Ed. CSIC. Madrid. 1992. 
BELLO, Andrés. Gramática. Prólogo de Amado Alonso. Ed. Ministerio de Educación, Caracas, Venezuela. 1951.

BENVENISTE, Emile. "Categories de pensée et categories de langues" (1958) en: Problemas de linguistique generale Vol. pag.63-64. Ed. Gallimard. París. 1966.

CÁNOVAS, R. "Curso de gramática sistemática". Inédito. Madrid. 1988.

CHOMSKY, Noam. Aspectos de la teoría de la sintaxis. Ed. Aguilar, Madrid. 1971.

CISNEROS, Luis Jaime. El funcionamiento del lenguaje. Ed. PUCP, Lima. 1995.

COSERIU, Eugenio. Lecciones de lingüistica general. Ed. Gredos. Madrid. 1981.

CRESPO, Emilio; CONTI, Luis; MAQUIEIRA, Helena. Sintaxis del griego clásico. Ed. Gredos. Madrid. 2003. 502 págs.

EMONDS, J; BOLINGER, D; NEWMEYER, F. J.; PONZIO, A. y otros en "Lingüística y Sociedad". Ed. Siglo XXI. 1976.

GÓMEZ ASENCIO, José J. Gramática y categorías verbales en la tradición española (1771-184). Salamanca, España. 1981.

GRANDGENT, C.H. Introducción al latín vulgar Ed.CSIC 1991. Madrid. 390 págs.

HERMAN, József. El latín vulgar. Ed. Ariel. Barcelona. España. 166 págs.

HERNÁNDEZ ALONSO, César. Gramática funcional del español. Ed. Gredos. Madrid. 1986.

HIERRO S.PESCADOR, José. Principios de Filosofía del lenguaje. Alianza Editorial Textos. Madrid. 1989. 
HJELMSLEV, Louis Lengua y habla. Separata Biblioteca Universidad Antonio Ruiz de Montoya. Lima.

HOCKETT, Carlos. Curso de lingüística moderna. Ed. Eudeba. Buenos Aires. 1971.

INCLÁN, Luis. Guía para traducir latin Ed. Octaedro. Barcelona. 1996. 63 págs. (fácil con lecturas y ejemplos)

JAKOBSON, Roman. Nuevos ensayos de lingüística general. Ed. Siglo XXI. Madrid. 1976.

LAZARO, F. y TUSÓN, V. Lengua española. Ed. Anaya. Madrid. 1989.

LEROY, Maurice. Las grandes corrientes de la lingüística. Ed. Fondo de Cultura Económica. México. 1985.

MALINBERG, Bertil. Los nuevos caminos de la lingüística. Ed. Siglo XXI. 251 págs.

MIRANDA, Luis. Curso de Lingüística general. UNMSM, Lima. 1993.

MORENO CABRERA, Juan Carlos. Semántica y Gramática. Sucesos, papeles semánticos y relaciones sintácticas. Ed. A. Machado Libros. Madrid. 2003.

RAMÍREZ, Luis Hernán. Estructura y funcionamiento del lenguaje. Ed. Studium. Lima. 1979.

RODRÍGUEZ ADRADOS, Francisco. Historia de la lengua griega. Ed. Gredos (1999). 320 págs.

RUBIO FERNÁNDEZ, Lisardo y GONZÁLEZ ROLÁN, Tomás. Nueva Gramática Latina. Ed. Coloquio.1990. Madrid. 327 págs. 
RUBIO, Lisardo. Nueva sintaxis latina simplificada Ed. Clásicas. Madrid. 1995. 102 págs.

SALAZAR GARCÍA, Ventura. Léxico y teoría gramatical en la lingüística del siglo XX.Ed. Sabir. Barcelona, España. 1998.

SAUSSURE, Ferdinand de. Curso de lingüistica general. Ed. Losada. Buenos Aires, Argentina. 1967.

SOLÍS FONSECA, Gustavo. Introducción en la Morfología. Ed. Concytec. Lima, Perú. 1994.

ULMANN Stephen. Semántica. Introducción a la ciencia del significado. Ed. Aguilar. Col. Cultura e historia. Madrid. 1967.

VILLIMER LLAMAZARES, Santiago. Sintaxis funcional de la lengua latina. Ed. Palas Atenea. Madrid. 105 págs. 